\title{
Herminio Barreiro: Recuerdos de cuando fue mi profesor
}

\author{
Felipe TRILLO ALONSO \\ Universidade de Santiago de Compostela
}

Son muy pocos los profesores de quienes sus alumnos se complacen y hasta presumen por haberlos tenido como tal. Herminio es uno de esos raros por escasos ejemplos.

Aún cuestionando algunas de sus afirmaciones, o precisamente por eso, y por ser incluso alentados a hacerlo por él mismo, la conclusión indubitable es que fue una suerte disfrutar de su magisterio.

Así, transcurridos más de treinta años desde entonces, y cuando ya uno ha forjado su propia biografía personal y profesional —también como él en el ámbito universitario-, no deja de llamar la atención que, sin rubor alguno, me complazca y hasta enorgullezca reconocerlo como uno de mis maestros en el plano académico e intelectual.

Desearía ser poeta para escribirle una elegía pero, torpe, me quedo en un opúsculo que se refiere esencialmente al modo como lo recuerdo cuando fue mi profesor.

Más tarde, ya compañeros, mantuvimos algunas discrepancias que enfriaron un poco nuestra relación, pero precisamente por ello tenga quizás más valor mi laudatio, al recuperar aquí y ahora la calidez de aquel tiempo en el que como alumno suyo disfrutaba de su compañía cual si de un privilegio se tratara.

Si ser maestro, a decir de Ortega, supone "remediar nuestra ignorancia con su saber", Herminio lo hizo. En un tiempo de formación (1975-1980), en el que los estudios de Pedagogía se movían todavía entre la pura abstracción especulativa y el mero dato empiricista, Herminio representó para nosotros el compromiso de la interpretación crítica. Frente al abuso de un lenguaje generalmente rancio y a veces casi esotérico, y la hipnosis de una metodología positivista tan engreída de su rigor (mortis), como enajenada de la realidad por reduccionista, su propuesta didáctica nos invitaba a una especie de simbiosis con los hechos que configuran la historia para asegurar la posibilidad de comprenderlos en toda su complejidad.

Por si fuera poco, lo suyo no era una arenga, sino un ejemplo. Así, su actuación en el aula no se limitaba a presentar la información, sino sobre todo a desarrollar su personal visión sobre la misma, pero no sólo exponiéndola, sino sobre todo desvelando las claves teóricas y conceptuales sobre las que se apoyaba para hacerlo. En ese sentido, él mismo 
se arriesgaba con valor a la potencial crítica de sus supuestos y, aunque es cierto que por nuestra juventud (como sinónimo de poco conocimiento e inexperiencia) no le cuestionábamos entonces como podríamos hacerlo ahora, lo cierto es que él nos animaba a ello y nos desafiaba incluso.

Valoro extraordinariamente aquella experiencia porque al llevarla a cabo nos estaba diciendo tácitamente y sin necesidad de verbalizarlo lo siguiente: creo en vosotros, en vuestra capacidad para discernir los mensajes y para elaborar una conclusión personal; esta es la mía, a ver cuál es la vuestra.

Por supuesto, algunos caracteres pusilánimes vieron en aquella forma de actuar una cierta imposición de su perspectiva, y lo que es más, de su ideología. Porque Herminio la tenía sin duda (no voy a clasificarla ni a enjuiciarla), y porque era vehemente en la defensa de su argumentación.

Sin embargo, no les di la razón entonces ni lo hago ahora a los que le criticaron, pues a Herminio le adornaban dos rasgos esenciales del intelectual de izquierda que siempre fue: la curiosidad y la tolerancia.

Él, que tanto tenía para contar, se mostraba ávido de escucharnos, expectante por descubrir lo que pensábamos, de tal suerte que nos provocaba constantemente para que se lo dijéramos. No era una pose ni paternalista ni condescendiente, sino un sincero interés por conocer nuestro parecer, yo diría incluso que por aprender de nosotros: cualquier cosa, lo que buenamente pudiéramos aportarle. Así, los que nos animábamos a decírselo sentíamos una satisfacción singular por merecer su atención, por ver como retenía nuestra idea y como le daba vueltas promoviendo un diálogo mayéutico que entusiasmaría al mismo Sócrates.

Tal es así, que si "el gran profesor lo es por su aptitud de dejarse renovar por sus discípulos" - como dijo Ortega-, Herminio también satisfacía con creces esa premisa.

Creo además que esto es lo que configuró el especial carisma de Herminio entre los estudiantes de diversas generaciones e hizo que, con el tiempo, se convirtiera en una especie de símbolo de sí mismo: el del "viejo profesor" siempre joven. Sí, posiblemente ese era el rasgo más distintivo de su personalidad docente.

Respecto a la tolerancia: diré que la primera vez que accedí a leer algo del Tratado sobre la Tolerancia de Voltaire fue gracias a Herminio. Aquello de "no estoy de acuerdo contigo, pero defenderé con mi vida tú derecho a expresarte", tal vez no lo escuché por vez primera en sus aulas, pero sí tuve la oportunidad de experimentarlo. Había algo en su manera de comportarse, incluso de acercarse a uno con movimientos suaves (casi felinos), que si algo ponía de manifiesto era su íntimo respeto por la persona a quien se dirigía. Es más, alguna vez me pareció verle algo así como enfadado con alguien por algún motivo y creí percibir que era él el que más padecía con esa situación. Su gesto podía ser serio, reconcentrado con frecuencia, pero alerta siempre a no cometer ningún tipo de desaire. Por su posición, talla intelectual y extraordinaria capacidad dialéctica le habría sido fácil 
hacer trizas los posicionamientos que le disgustaban o que simplemente no compartía, y sin embargo jamás le vi que hiciera tal cosa.

Por ese rasgo de su carácter, estudiantes de diversas épocas, procedencias, intereses e incluso ideologías, ya fueran incipientes o consolidadas y no importaba cuan cerca 0 alejadas estuvieran de la suya, podían acercarse a él con confianza y hacerlo además en cualquier lengua.

Mención singular merece esto último, porque la suya con la lengua fue siempre para mí una conducta ejemplar; una vez más sin verbalizarlo venía a decirnos que lo que le importaba era que nos expresáramos en primer lugar y después el contenido y la entidad de lo que dijéramos. La lengua en la que lo hiciéramos era secundario y, por ello, Herminio siempre era el primero en adaptarse a la lengua de su interlocutor sin hacer casus belli de su uso. Hubo tiempos en los que esto no era políticamente correcto y, sin embargo, Herminio permaneció fiel a sí mismo.

En línea con la apertura de su pensamiento, la puerta de su despacho permanecía siempre abierta para nosotros. Acercarse al mismo para conversar con él, oteando su rostro detrás de la cortina del humo del tabaco y de la muralla de libros siempre perfectamente alineados sobre su mesa, tenía algo de iniciático para un joven de veinte años, como si aquello fuera una especie de sancta sanctorum. La atmósfera tenía su impronta: aquel era un espacio para el estudio, para el pensamiento, para el diálogo sosegado.

Con todo, llegado aquí temo haber dado una imagen excesivamente complaciente de Herminio. En la que atesoro en mi memoria, sin embargo, había cosas de él —cuando yo era su alumno-, que como mínimo me desconcertaban un poco. Por entonces no supe resolver si eran contradicciones o pequeñas fisuras en la coherencia de una arquitectura intelectual que yo intuía más institucionista que otra cosa. Pero tampoco importa porque a la postre, en aquellos tiempos que rememoro, esos detalles lo hacían más interesante si cabe, y desde luego más humano y accesible también. Me refiero a un cierto radicalismo suyo en cuanto al apego por el uso de la lógica marxista y a la defensa de determinadas causas que, como la de Fidel Castro en Cuba, a mí ya entonces me provocaba cierto estupor.

En efecto, había también - pero siempre fuera de clase- un Herminio beligerante a favor de las reivindicaciones de las organizaciones de izquierda (sindicatos y partidos, primero sin legalizar y después legalizados). En las conversaciones de café donde se extendía de alguna manera su magisterio, aunque ya sólo para los que voluntariamente queríamos permanecer con él - a salvo por tanto de la severa mirada de Max Weber advirtiendo a los profesores que no conviertan su tarima en un púlpito-, Herminio desgranaba historias sobre las ilusiones de la República, la crueldad de la guerra civil, las vejaciones de la postguerra, la resistencia al régimen de Franco, y las alternativas comunistas al capitalismo, entre otras muchas cosas que, debo decirlo, sirvieron para abrirme los ojos a una realidad que desconocía. Y lo hacía con tal profusión de detalles, de referencias, de 
lecturas, de frases y de anécdotas, que escucharlo tenía sus efectos: a mí, por ejemplo, me embriagaba, pero a otros más proclives a su causa realmente les enfervorizaba.

Conste, no obstante, que Herminio no hacía proselitismo, pues ni siquiera en esos momentos renunciaba a que fuéramos nosotros los que concluyéramos libremente. El era un bardo, jamás un encantador de serpientes. En todo caso, interesa destacar que era en aquellos momentos en los que el Herminio independiente que yo imaginaba cual un lobo estepario, se me revelaba por el contrario como un hombre de grupo que, como dijo el poeta, "sabe su doctrina".

En el aula Herminio era muchísimo más mesurado en cuanto a la dimensión política de sus análisis de los hechos históricos. Estos, por otra parte, siempre tenían protagonistas y contextos: no eran ideas abstractas enajenadas de las voces que las pronunciaron y de las realidades que las provocaban y urgían. Herminio presentaba a los personajes de la historia de la educación de tal manera que concitaban nuestros afectos, nuestra solidaridad o nuestra repulsa. Del mismo modo, los contextos recreados por él, se convertían en espacios en los que las fuerzas de la opresión y de la libertad pugnaban entre sí por la hegemonía, reclamando nuestra participación. Siendo así, yo diría que no le importaba tanto el rigor científico (con su inevitable tasa de asepsia) como sacudir nuestra indiferencia. Rousseau frente al estigma del Leviatán, Pestalozzi creando un estado y una sociedad nueva desde la escuela, la Escuela Nueva como potencial antídoto a las guerras fraticidas y, sobre todo, la Institución Libre de Enseñanza como una ética laica que liberaba las conciencias, son algunas de sus más brillantes e inolvidables lecciones.

En esa dirección de estimular nuestra reflexión y posicionamiento, nuestro aprendizaje en suma, Herminio aprovechaba los recursos de su capacidad dramática, que era sencillamente extraordinaria. Tanto que no necesitaba de ninguna especial puesta en escena, tampoco de ningún tipo de artilugios. Con solo las inflexiones de su voz y el balanceo de sus manos conseguía captar nuestra atención como ninguno: incluso sentado tras su mesa y en lo alto de la tarima. Alguna pequeña digresión en clave de humor para relajar y enseguida de nuevo al asunto, que el revivía y representaba para nosotros con mal disimulada pasión. Recuerdo así un momento álgido de su pericia comunicativa: lo fue para mí cuando nos leyó la necrológica que Don Antonio Machado escribió por la muerte de Don Francisco Giner de los Ríos. En el aula regía un silencio sepulcral y cómplice. Como sería que treinta y muchos años más tarde aún me conmuevo cuando recuerdo a Herminio mientras nos leía:

Como se fue el maestro

la luz de esta mañana

me dijo: van tres días que mi hermano Francisco no trabaja.

¿Murió?... Sólo sabemos

que se nos fue por una senda clara,

diciéndonos: Hacedme

un duelo de labores y esperanzas.

Sed buenos y no más, sed lo que he sido 
entre vosotros: alma.

Vivid, la vida sigue,

los muertos mueren y las sombras pasan,

lleva quien deja y vive el que ha vivido.

¡Yunques, sonad; enmudeced, campanas!

En fin, he volado en el tiempo hasta los años 1978 y 1979. ¡Quien me iba a decir que releería estos versos pensando en él! Con los retales (jamás jirones) encontrados en mi memoria, he descrito a un Herminio de carne y hueso que fue mi profesor. Un maestro en cuyos modos me reconozco a mi mismo, siquiera como proyecto (todavía y siempre), y es por eso que me reitero y digo: que me siento obra suya de alguna manera. Por todo ello, gracias Herminio. 